\section{Adhesive Grafting of Chinese Cabbage on Turnip}

\author{
Masayuki Oda \\ Department of Applied Physiology, National Research Institute of \\ Vegetables, Ornamental Plants and Tea, Ano, Mie 514-23, Japan

\section{Tatsuto Nakajima \\ Applied Plant Research Laboratory Japan Tobacco Inc., Oyama, Tochigi 323, Japan}

Additional index words. Brassica rapa, 2-cyanoacrylate, polyalkylenglycol
Grafted plants have been used for the production of fruit-bearing vegetables and are used in Japan (VOCRS, 1981). Oda et al. (1990) analyzed possible combinations of scions and rootstocks for leafy and root crops in the family Cruciferae.

In our study, an adhesive (Morita, 1988) and hardener system was used for the grafting of very young Chinese cabbage plants to small turnip plants. The possibility of adhesive grafting was investigated from the viewpoint of survival and anatomical characteristics of the grafted plants.

Seeds of Chinese cabbage [Brassica rapa L. (Pekinensis group) 'Taibyoh 60-nichi', Takii Seed Co., Kyoto, Japan] and turnip [B. rapa L. (Rapifera group) 'Taibyoh hikari', Takii Seed Co.] were sown in $700-\mathrm{cm}^{3}$ plastic pots filled with andosol soil amended with $1 \mathrm{~g}$ fertilizer $(14 \mathrm{~N}-18 \mathrm{P}-16 \mathrm{~K})$ per pot on 19 Aug. 1989. The seedlings were cut horizontally below the cotyledons with a sharp razor blade on 1 Sept., when two leaves had expanded in Chinese cabbage (scion) and turnip (rootstock). The cut surfaces of the scion and rootstock were connected to each other, and the part around the connected hypocotyls was surrounded with an adhesive, followed by the spray of a hardener. The adhesive and hardener system (Toagousei Chemical, Tokyo) consisted of alkyl 2-cyanoacrylate and polyalkylenglycol derivatives, respectively. As the control, the cut end of the rootstock was cleft with a sharp razor blade, and the tapered hypocotyl of the scion was inserted into the cleavage zone and supported with a graft-clip. Twelve grafts in each treatment were placed in a plastic container, with a water layer at the bottom to maintain high humidity in the container. The container was covered with polyethylene film and shaded with a cheesecloth. The film and cheesecloth were gradually removed after 3 days of healing and were completely removed after 7 days of acclimatization. The survival ratio was calculated by counting the number of grafted

Received for publication 14 Aug. 1991. Accepted for publication 13 Apr. 1992. The cost of publishing this paper was defrayed in part by the payment of page charges. Under postal regulations, this paper therefore must be hereby marked $a d$ vertisement solely to indicate this fact. plants that survived. These were then transplanted to $3800-\mathrm{cm}^{3}$ Wagner pots and grown until the tap roots thickened and heads were formed. The graft-clip was removed at plantmg time, while the adhesive naturally cracked off during cultivation. On 9 Oct., the grafted plants were harvested and the vascular bundles were stained by dipping the cut surfaces of the thickened roots in $0.5 \%$ methylene blue for a day. The demarcation zone between the scion and rootstock was frozen, cut into $20-\mu \mathrm{m}$-thick slices, and the parenchyma tissue of the sliced sample placed on a glass slide stained with $1 \%$ orcein.

Survival ratios in each treatment were similar (50\%). This low survival ratio may be due to the fact that the plants for grafting were too small to handle successfully.

Tap roots of the grafted plants thickened and heads were formed (Fig. 1A). However, the head size was small at the time the turnip was harvested, because thickening of turnip tap roots started immediately after acclimatization, whereas heading of the Chinese cabbage began $\approx 50$ days later.

Cavities were observed at the demarcation zone between scion and rootstock in all plants grafted by the cleft or horizontal (Fig. 1B) method. However, the vascular bundles of the scion and the rootstock were tightly connected (Fig. 1C). The ability of the weak demarcation zone under field conditions to withstand mechanical forces and attack by wise, the effect of the cavity on the movement of synthates has not been assessed.

\section{Literature Cited}

Morita, S. 1988. A new method of grafting by the application of adhesive in fruit vegetables (in Japanese). Agr. Hort. 63:1190-1196.

Oda, M., K. Tsuji, and M. Nagaoka. 1990. Intergeneric, specific and varietical grafting in $\mathrm{Cru}$ ciferae. Proc. XXIII Intl. Hort. Congr. (1), Firenze, Italy, 27 Aug.-1 Sept. 1990:205.

Vegetables and Ornamental Crops Research Station (VOCRS). 1981. Problems in the cultivation using grafted plants (in Japanese). Materials collected by Veg. \& Ornamental Crops Res. Stnd., no. 11. pathogens has not been determined. Like-

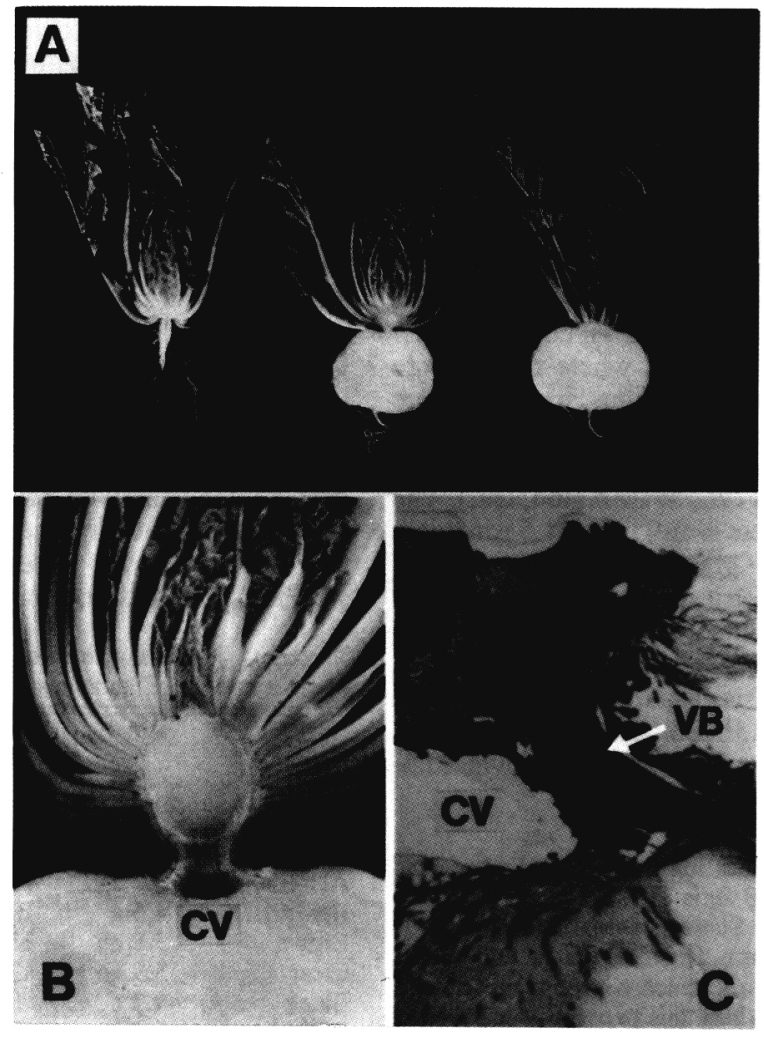

Fig. 1. Anatomy of grafted plant, whose scion and rootstock consist of Chinese cabbage and turnip, respectively. (A) Grafted plant (center) obtained by the grafting of Chinese cabbage (left) on turnip (right); (B) Cavity (CV) formed at the demarcation zone between the scion and the rootstock; (C) Vascular bundle (VB) connection between the scion and the rootstock. 